\title{
BMJ Open Laparoendoscopic single-site surgery compared with conventional laparoscopic surgery for benign ovarian masses: a systematic review and meta- analysis
}

Yun Lin (D) , ${ }^{1,2}$ Mubiao Liu, ${ }^{1}$ Haiyan Ye, ${ }^{1}$ Jianhui He, ${ }^{1}$ Jianguo Chen ${ }^{1}$

To cite: Lin Y, Liu M, Ye H, et al. Laparoendoscopic single-site surgery compared with conventional laparoscopic surgery for benign ovarian masses: a systematic review and meta-analysis. BMJ Open 2020;10:e032331. doi:10.1136/ bmjopen-2019-032331

- Prepublication history and additional material for this paper are available online. To view these files, please visit the journal online (http://dx.doi. org/10.1136/bmjopen-2019032331).

Received 16 June 2019 Revised 16 December 2019 Accepted 20 December 2019

A) Check for updates

(c) Author(s) (or their employer(s)) 2020. Re-use permitted under CC BY-NC. No commercial re-use. See rights and permissions. Published by BMJ.

${ }^{1}$ Department of Gynecology, Guangdong Provincial People's Hospital, Guangdong Academy of Medical Sciences, Guangzhou, Guangdong, China ${ }^{2}$ Shantou University Medical College, Shantou, Guangdong, China

Correspondence to Jianguo Chen;

chenjgphd@163.com

\section{ABSTRACT}

Objective We aimed to evaluate the safety, efficiency and preferred indication for laparoendoscopic single-site surgery (LESS) compared with conventional laparoscopic (CL) surgery for benign ovarian masses.

Design A systemic review and cumulative metaanalysis were performed in line with the criteria of Grading of Recommendations Assessment, Development and Evaluation: levels of evidence and grades of recommendation.

Data sources We comprehensively searched the electronic databases including PubMed, Medline, Embase and the Cochrane Library in November 2018.

Eligibility criteria for selecting studies We included all randomised controlled trials (RCTs) and retrospective studies published in recent 10 years, which investigated the performance of LESS versus CL in patients at all ages with benign ovarian masses.

Results Four RCTs and nine retrospective studies published in recent decade including 1542 cases (744 cases for LESS and 798 cases for CL) were identified. Perioperative complication was consisted of intraoperative and postoperative complications, including ileus, wound infection or dehiscence and incisional hernia. Although LESS has less postoperative analgesic consumption (46.78\% and $79.25 \%$; 0R: $0.49 ; 95 \% \mathrm{Cl}: 0.33$ to 0.74 , $\mathrm{p}<0.001$ ) and shorter hospital stay (weighted mean difference (WMD): -0.24 days; $95 \% \mathrm{Cl}:-0.35$ to -0.14 ; $\mathrm{p}<0.001)$, CL has less perioperative complications $(6.59 \%$ and 2.85\%; OR: 2.08; 95\% Cl: 1.05 to $4.11, \mathrm{p}=0.04$ ) and shorter operative time (WMD: $3.43 \mathrm{~min} ; 95 \% \mathrm{Cl}:-0.03$ to $6.88 ; p=0.05)$. Body mass index, history of previous abdominal surgery, size of adnexal mass, estimated blood loss and postoperative pain scores did not differ significantly between two techniques.

Conclusions The indications of LESS for benign ovarian masses are similar to $\mathrm{CL}$ and it has better postoperative recovery. However, with less perioperative complications, CL surgery is safer than LESS.

\section{INTRODUCTION}

Benign ovarian masses are common health problems of women and laparoscopic surgery was the common method of choice.
Strengths and limitations of this study

- This is the first meta-analysis focused on benign ovarian masses to review all available literature.

- We employed rigorous methodology that followed a protocol developed a priori according to the Preferred Reporting Items for Systematic Reviews and Meta-Analyses statement, and used the Grading of Recommendations Assessment, Development and Evaluation approach in the review process.

- There are only four randomised controlled trials with small sample sizes.

- No subgroup analysis was performed among different histologic types of ovarian masses.

Laparoscopy has significant advantage over laparotomy, including enhanced cosmetic results, less postoperative pain and shorter recovery times. In the conventional laparoscopy (CL), at least three accessory ports were needed for surgical operation placing in the umbilicus and two inguinal regions. Since the first report of the single umbilical puncture laparoscopy by Pelosi and Pelosi in 1991, ${ }^{1}$ laparoendoscopic single-site surgery (LESS) became popular in the last two decades because it was even less invasive than CL. LESS involves the use of only one small incision, usually at the umbilicus, so the assess scar was hidden into the umbilicus to achieve better cosmetic effect. ${ }^{2}$

Although the feasibility of LESS on benign ovarian masses was confirmed, it is uncertain whether the benefits of LESS, compared with CL surgery, are only restricted to improved cosmesis. As multiple laparoscopic tools gathering into a small space, it may increase the difficulty of operation. We need evidence to prove whether the incidence of surgical complications increase in LESS or not. Therefore, the aim of this systematic 
review was to analyse all available literatures and provide pooled estimations of evidence regarding the safety, efficiency and preferred indication of LESS compared with CL.

\section{METHODS \\ Search strategy}

A literature search was performed in 24 November 2018 without restriction to languages, regions or article types. The prospective protocol of searching strategies, inclusion and exclusion criteria and the methods of statistical analysis were prepared in advance according to the Preferred Reporting Items for Systematic Reviews and Meta-analysis. ${ }^{3}$ The electronic databases including PubMed, Embase, Medline and the Cochrane Library were searched for all studies. Only studies published from 24 November 2008 to 24 November 2018 were included. The following MeSH terms were searched: laparoendoscopic single site/port/hole/incision surgery, conventional/ traditional laparoscopic and benign ovarian tumour/ cyst/masses/adnexal disease/endometriosis/ovarian chocolate cyst/endometriotic ovary. All available clinical studies were searched by the Related-Articles function. The reference lists were exported into a reference management software, Endnote X9, and the duplicates were deleted. An example of search terms for PubMed is included in online supplementary file 1 .

\section{Inclusion and exclusion criteria}

All available randomised controlled trials (RCTs), cohort studies and case-control studies on investigating the performance of LESS versus CL in patients at all ages with benign ovarian masses published in recent 10 years, were included. Reviews, case reports and letters to the editor were excluded.

\section{Data collection}

Data from each included study were extracted independently by two of the authors (YL and JH). Any disagreement was resolved through extracting data from the article by the adjudicating senior authors (JC and ML).

The primary outcome measures were perioperative complication rates, postoperative pain, operative time $(\mathrm{min})$ and estimated intraoperative blood loss $(\mathrm{mL})$. The secondary outcome measures were length of hospital stay (days), size of adnexal masses $(\mathrm{cm})$, body mass index (BMI, $\mathrm{kg} / \mathrm{m}^{2}$ ) and previous abdominal surgical history. The postoperative pain scores were assessed using visual analogue pain scale (VAS), scored from 0 to $10(0=$ no pain and $10=$ agonising pain). The definition of postoperative complications was any symptoms related to the surgery that patients complained after the operation, including ileus, wound infection or dehiscence and incisional hernia.

\section{Quality assessment}

All included studies were assessed by Review Manager V.5.3 in line with the criteria of Grading of Recommendations Assessment, Development and Evaluation: levels of evidence and grades of recommendation. ${ }^{4}$ The quality of RCTs was assessed by the Cochrane risk of bias tool and all retrospective studies were assessed by the NewcastleOttawa scale (NOS). ${ }^{56}$ A score of $0-9$ was allocated to each retrospective study, and higher quality score means higher quality of retrospective study. All RCTs and the retrospective studies which achieving six or more stars were considered of high quality. Two reviewers (YL and $\mathrm{JH}$ ) assessed the quality of all studies. Where discrepancies arose, papers were reviewed and agreed conclusion was reached by discussion with two adjudicating senior authors (JC and ML).

\section{Statistical analysis}

The results of all studies included continuous variables and dichotomous variables, which were reported with $95 \%$ CI. The WMD was used to summarise the differences of continuous variables, and OR was used to compare dichotomous variables. For some studies that presented continuous data as means and range values, SD were calculated with statistical algorithms described by Wan $e t$ $a l^{7}$

Statistical heterogeneity between studies was assessed by the $\chi^{2}$ test $\left(\chi^{2}\right.$ statistic) and quantified by the $\mathrm{I}^{2}$ statistic. ${ }^{8}$ Higher $\mathrm{I}^{2}$ and $\chi^{2}$ statistic indicates greater heterogeneity between studies. The random effects model was used for this meta-analysis if there was heterogeneity between included studies, which the $\mathrm{p}$ value was less than 0.1 . Otherwise, the fixed effects model was used. ${ }^{6}$ Sensitivity analyses were performed for high-quality studies. Funnel plot was used to screen the potential publication bias. $P$ value less than or equal to 0.05 was considered as statistically significant.

\section{RESULTS}

A total of 165 publications were identified as the search strategy summarised in figure 1 . Agreement between the two reviewers was $100 \%$ for study selection and $92.3 \%$ for quality assessment of trials. Thirteen studies including 1542 cases ( 744 cases for LESS and 798 cases for CL) fulfilled the predefined inclusion criteria for metaanalysis. All the 13 studies were full-text articles published from 2011 to 2017. We confirmed that all the references for these studies and the review articles did not yield any another studies for evaluation.

\section{Characteristics of the included studies}

The characteristics of these 13 studies, including four RCTS $^{9-12}$ and nine retrospective studies, ${ }^{13-21}$ are shown in tables 1 and 2. The geographic distribution of these study institution was varied, with seven reports from Korea, two from Italy and one from America, England, China and Turkey, respectively. 


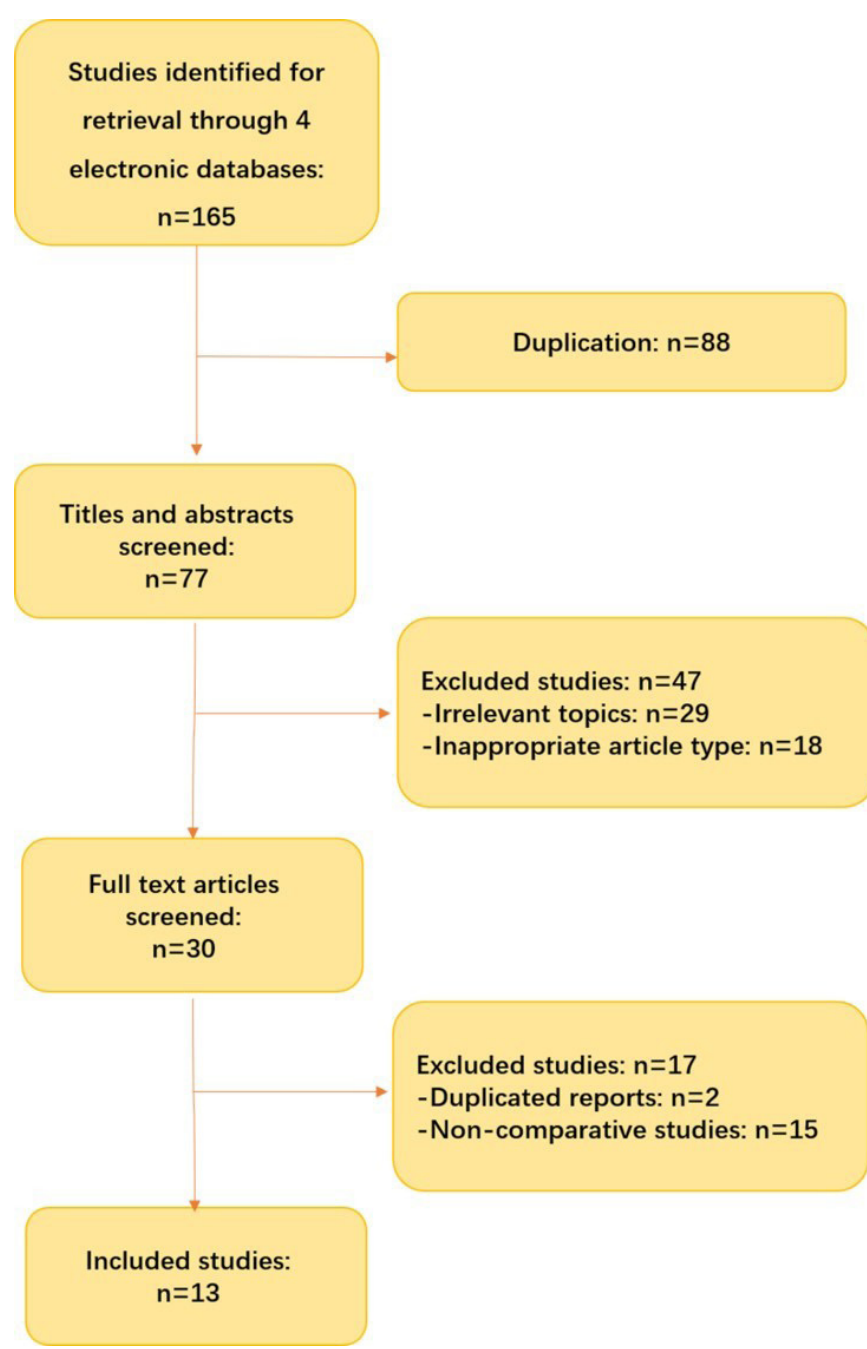

Figure 1 Search strategy of studies identified, included and excluded.

The quality scores of the included observational studies were ranged from 6 to 9 with a mean score of 7 , which suggested the relatively high quality in the metaanalysis (table 2). All studies described randomisation and methods of random sequence generation, however, one did not mention the allocation concealment ${ }^{10}$ and a half of studies did not provide the information about the blinding method. Regarding the RCTs, the lowest agreement was achieved in the incomplete outcome data, while the perfect agreement was achieved in the selective reporting. The risk of bias of each RCT was showed in figures 2 and 3 .

\section{Primary outcome}

\section{Perioperative complications}

Nine studies ${ }^{9-15} 1920$ including 846 patients reported perioperative complications. In the pooled analysis, LESS group had more perioperative complications than CL group (6.59\% and 2.85\%; OR: 2.08; 95\% CI: 1.05 to 4.11, $\mathrm{p}=0.04$ ) (table 3 figure 4). Intraoperative complication was mentioned only in three studies, but all of these studies reported that no complications occurred during the operation. Twenty-eight patients encountered postoperative complications in LESS group, and the most common postoperative complication was ileus $(10 / 28)$. On the other hand, complications occurred in 12 patients in the CL group, and two of them were ileus. A quarter of complications in LESS group were wound infection or wound dehiscence $(7 / 28)$, while none occurred in CL group. Besides, more patients in CL group developed abdominal wall haematoma near the incision site than LESS group (3/12 vs 1/28).

\section{Postoperative pain}

Seven studies ${ }^{9-12} 151719$ including 1033 patients evaluated postoperative pain scores using VAS at 4 hours after the end of surgery. There was no significant difference between the two groups (WMD: $-0.28 ; 95 \%$ CI: -0.62 to $0.05 ; \mathrm{p}=0.10)$. There was significant difference between study heterogeneity $\left(\chi^{2}=17.93, \mathrm{df}=6, \mathrm{p}=0.006 ; \mathrm{I}^{2}=67 \%\right)$ (figure 5). However, there was significant difference in postoperative analgesic consumption, and the LESS group had lower analgesic requirement $(46.78 \%$ and $79.25 \%$; OR: 0.49 ; $95 \%$ CI: 0.33 to $0.74, \mathrm{p}<0.001$ ).

\section{Operative time}

All studies ${ }^{9-21}$ reported operative time for 1542 patients, and the LESS group had longer operative time than the CL group (WMD: $3.43 \mathrm{~min}$; $95 \%$ CI: -0.03 to 6.88 ; $\mathrm{p}=0.05$ ). Significant heterogeneity was found between these studies $\left(\chi^{2}=34.85, \mathrm{df}=12, \mathrm{p}<0.001 ; \mathrm{I}^{2}=66 \%\right)($ figure 6$)$.

\section{Estimated intraoperative blood loss}

Pooling the data of all studies that reported the estimated intraoperative blood loss showed no significant difference between two groups (WMD: $-8.77 \mathrm{~mL}$; $95 \%$ CI: -40.81 to 23.26; $\mathrm{p}=0.59$ ), with significant difference between study heterogeneity $\left(\chi^{2}=34.24, \quad \mathrm{~d}=11, \quad \mathrm{p}<0.001 ; \quad \mathrm{I}^{2}=100 \%\right)$ (figure 7).

\section{Secondary outcome}

Length of hospital stay

Seven studies ${ }^{11-13} 16-1820$ reported length of hospital stay in 816 patients, and the pooled data showed a significant difference favouring the LESS group (WMD: -0.24 days; $95 \%$ CI: -0.35 to $-0.14 ; \mathrm{p}<0.001$ ) (figure $8 \mathrm{~A}$ ).

Size of adnexal masses, BMl and previous abdominal surgical history

The size of adnexal masses was objectively assessed in 11 studies $^{10-18} 2021$ that investigated 1313 patients (figure $8 \mathrm{~B}$ ), and there was no significant difference between the LESS and CL groups (WMD: $-0.21,95 \% \mathrm{CI}:-0.68$ to 0.26 ; $\mathrm{p}=0.38$ ). In terms of BMI reported in all 13 studies, ${ }^{9-21}$ there was no significant difference between the LESS and CL groups (WMD: $-0.02,95 \% \mathrm{CI}$ : -0.32 to 0.29 ; $\mathrm{p}=0.90$ ) (figure $8 \mathrm{C}$ ). Nine studies included 956 reported the history of previous abdominal surgery and showed no significant difference between both groups $(25.47 \%$ and 27.25\%; OR: 0.99; 95\% CI: 0.73 to $1.34, \mathrm{p}=0.94$ ) (figure 8D). 
Table 1 Characteristics of RCTs

\begin{tabular}{|c|c|c|c|c|c|}
\hline \multirow[b]{2}{*}{ Study } & \multirow[b]{2}{*}{ Year } & \multirow[b]{2}{*}{ Type } & \multicolumn{2}{|c|}{ Patients, no } & \multirow[b]{2}{*}{ Matching* } \\
\hline & & & LESS & CL & \\
\hline Cho et $a l^{10}$ & 2012 & RCT & 33 & 30 & $1,2,3$ \\
\hline Hoyer-Sørensen et al ${ }^{9}$ & 2012 & $\mathrm{RCT}$ & 20 & 20 & $1,2,3$ \\
\hline Karasu et al ${ }^{11}$ & 2017 & $\mathrm{RCT}$ & 32 & 39 & 1,2 \\
\hline
\end{tabular}

${ }^{*} 1$, age; 2 , body mass index; 3 , previous abdominal surgery history; 4 , single surgeon.

$\mathrm{CL}$, conventional laparoscopic surgery; LESS, laparoendoscopic single-site surgery; RCT, randomised controlled trials.

\section{Publication bias}

A funnel plot of all included studies in this meta-analysis was made for visual screening of any publication bias (figure 9). It revealed that all included studies were distributed around the vertical within the $95 \%$ CIs, suggesting no obvious publication bias.

\section{Study heterogeneity}

All included retrospective studies were scored at least six stars on the NOS. Therefore, no sensitivity analysis was needed in this meta-analysis. The heterogeneity between all studies was statistically significant for postoperative pain scores, operative time, estimated blood loss, adnexal mass size and previous abdominal surgical history, while perioperative complications, length of hospital stay and body mass index were comparable between studies.

\section{DISCUSSION}

This meta-analysis of four RCT and nine retrospective studies including 1542 patients aimed to compare the efficacy of LESS and CL surgery for benign ovarian masses. The result shows that LESS has better postoperative recovery but CL is safer. To be specific, there was significantly reduced postoperative analgesic consumption and shorter hospital stay in LESS group. However,
CL has less complications and shorter operative time. We found that there were no significant differences in BMI, history of previous abdominal surgery, size of adnexal mass, estimated blood loss and postoperative pain scores of patients in the LESS group and CL group.

In the clinical characteristics of the patients, there are no significant difference between LESS and CL surgery. LESS is a more challenging technique for surgeons compared with CL surgery due to several limitations like loss of triangulation, reduced visualisation and instrument interference. ${ }^{22}$ Thus, LESS was thought to be stricter in patient selection. ${ }^{23}$ Patients with smaller adnexal mass and without obese or previous abdominal surgical history are preferred. ${ }^{24}$ However, we found that there were no significant difference in these characteristics of patients. As some studies reported that disease features and patients' features would not been the limitation of LESS. ${ }^{25}$ Song et $a l^{26}$ successfully performed LESS for ovarian cysts with a minimal diameter at less $15 \mathrm{~cm}$ with few complications occurred and they concluded that the size is not a necessary contraindication for LESS of ovarian masses. Fanfani et $a l^{27}$ reported that LESS can be effectively and safely performed in obese patients $(\mathrm{BMI} \geq 30)$ without increased operative complications. Springer $e t a l^{28}$ also found that LESS in patients with previous abdominal surgery is

Table 2 Characteristics of the retrospective studies

\begin{tabular}{|c|c|c|c|c|c|c|}
\hline \multirow[b]{2}{*}{ Study } & \multirow[b]{2}{*}{ Year } & \multirow[b]{2}{*}{ Type } & \multicolumn{2}{|c|}{ Patients, no } & \multirow[b]{2}{*}{ Matching ${ }^{\star}$} & \multirow[b]{2}{*}{ Quality score } \\
\hline & & & LESS & CL & & \\
\hline Angioni et $a^{21}$ & 2015 & Case-control & 49 & 50 & $1,2,3$ & 9 \\
\hline Chong et $\left.a\right|^{20}$ & 2015 & Cohort & 25 & 30 & $1,2,3$ & 8 \\
\hline $\operatorname{Im}$ et $\left.a\right|^{13}$ & 2011 & Case-control & 18 & 15 & $1,2,3,4$ & 7 \\
\hline Lee et $a l^{18}$ & 2010 & Cohort & 17 & 34 & $1,2,3$ & 8 \\
\hline Park et $a l^{17}$ & 2015 & Cohort & 154 & 189 & 2,3 & 6 \\
\hline Wang et $a l^{16}$ & 2016 & Case-control & 99 & 104 & $1,2,3,4$ & 7 \\
\hline Yim et $a l^{15}$ & 2012 & Case-control & 110 & 107 & $1,2,3$ & 6 \\
\hline
\end{tabular}

Matching* : 1 , age; 2 , body mass index; 3 , previous abdominal surgery history; 4 , single surgeon.

Score assessed by Newcastle-Ottawa scale (range: 0-9).

LESS, laparoendoscopic single-site surgery; CL, conventional laparoscopic surgery. 


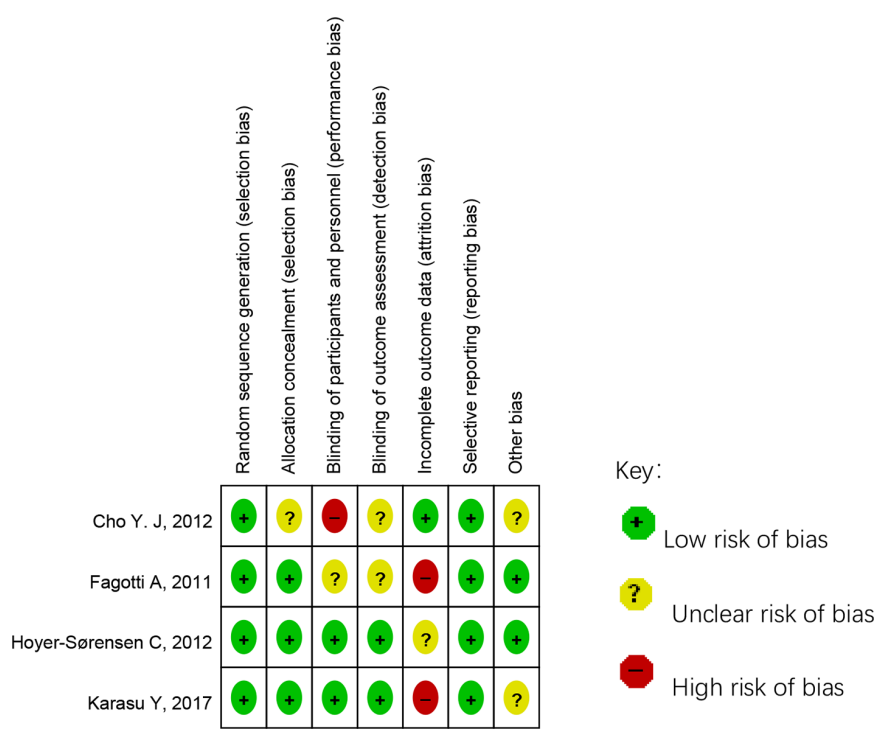

Figure 2 Quality assessment of each randomised controlled trial based on the Cochrane Collaboration's tool for risk of bias.

equally effective as CL. These may result from the advance of surgical skills and the development of technical instruments. The development of new devices for LESS (eg, flexible and streamlined optics, prebent instruments and wound retractor) will surely reduce the technical difficulties. Therefore, LESS for benign ovarian mass is feasible and the indications of LESS are similar to CL. ${ }^{23}$

The evaluation of perioperative complications is always of great importance in the application of any procedure, which is closely related to the safety of patients. Although some of the above studies reported that the complications were comparable between the LESS group and CL group in obese patients, the pooled data in this meta-analysis of perioperative complications indicate that CL surgery is safer than LESS for benign ovarian masses. Moreover, the operative time of LESS is longer than CL. Prolonged operative time leads to a long duration of pneumoperitoneum and anaesthesia, which may increase the incidence of perioperative complications, such as paralytic ileus. ${ }^{29}$ Jeung and colleagues found that postoperative ileus occurred in patients who underwent laparoendoscopic single-site total laparoscopic hysterectomy when

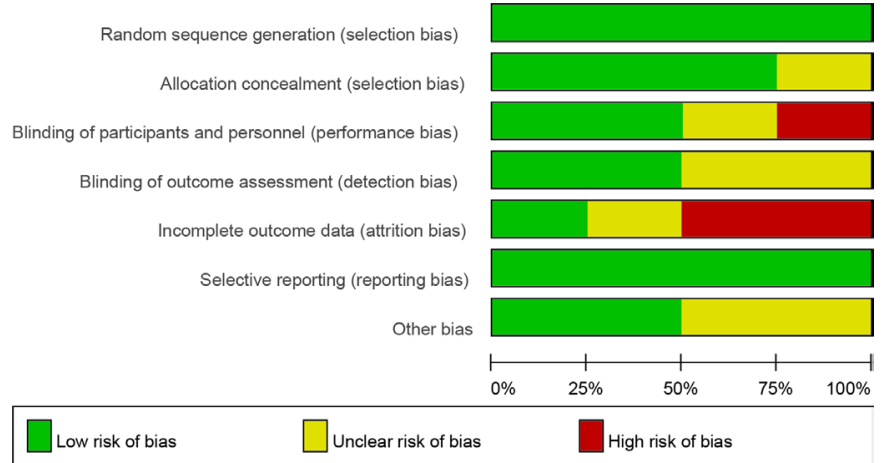

Figure 3 Methodological quality graph of all randomised controlled trials.

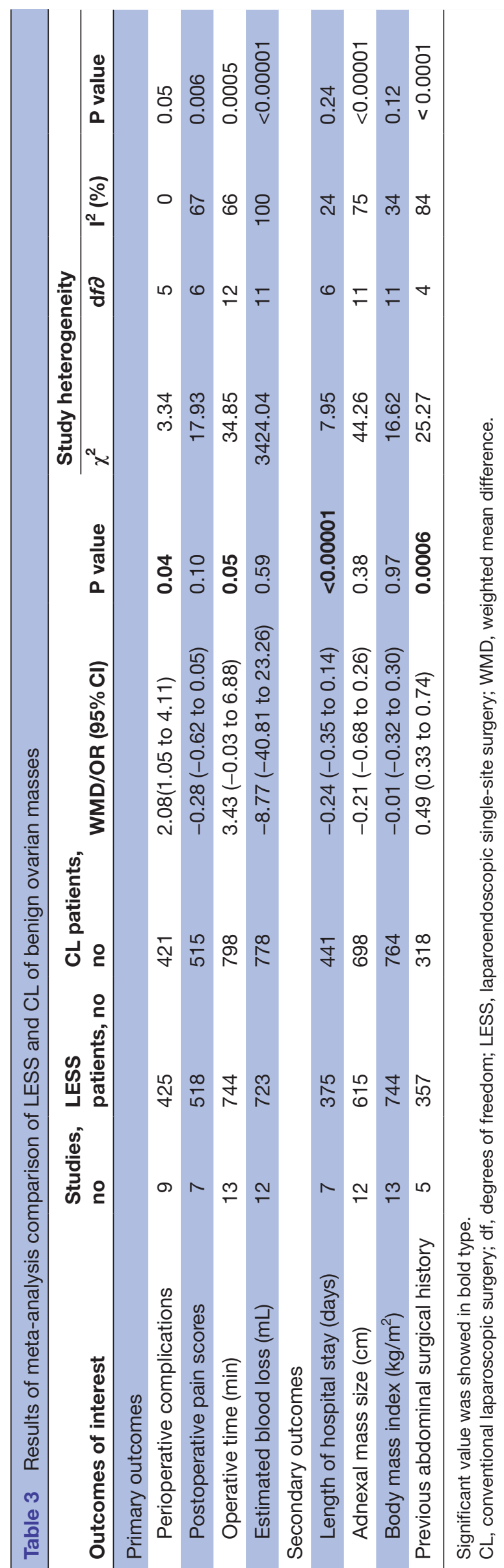




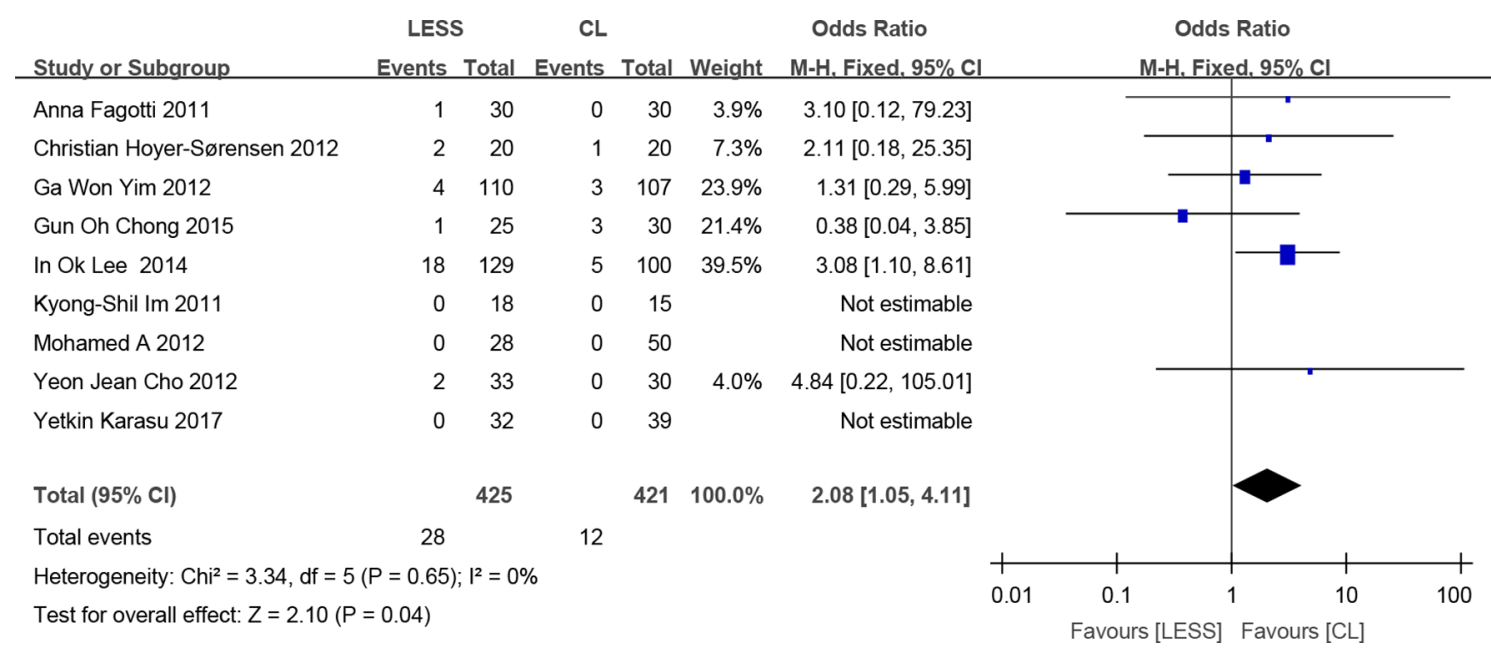

Figure 4 Forest plot and meta-analysis in evaluation of perioperative complications compared between LESS and CL of benign ovarian masses. CL, conventional laparoscopic surgery; LESS, laparoendoscopic single-site surgery, M-H, MantelHaenszel.

operative times was longer than 150 min, while no ileus occurred in the group with surgical time less than then 150 min. ${ }^{30}$ Nevertheless, the topic remains controversial and more investigations are needed to verify the relationship between ileus and LESS. Besides, when performing a LESS, all the instruments enter the peritoneal cavity through the umbilicus, and clashing of the instruments may increase when operating on lateral structures compared with medial ones. ${ }^{31}$ Therefore, CL surgery may be safer than LESS for benign ovarian masses.

Since only a single incision was required for LESS, improved cosmesis is an apparent advantage compared with CL surgery. ${ }^{32}$ In this meta-analysis, we were unable to evaluate this variable since no data were reported in the included studies. Oppositely, we found LESS may be more likely to cause wound infection or wound dehiscence, while no similar case was reported in CL group. A recent metaanalysis of 19 RCTs, including 1705 patients, suggested a slightly higher incidence of incisional hernia after LESS compared with CL.Marks et $a l^{33}$ performed a multicentre RCT including 119 procedures and found that the rate of incisional hernia for LESS was $8.4 \%$. Several studies also reported that the development of incisional hernia was increased after LESS at long-term follow-up. ${ }^{34}$ While for
CL surgery, this rate ranged from $0.3 \%$ to $5.4 \%,{ }^{36}$ which is significantly lower than LESS. The larger umbilical incision of LESS may be the reason for more wound complications. Higher forces are applied on umbilical port in LESS and it may cause irreversible umbilical deformation during tissue handling. ${ }^{37}$ The result emphasises the importance of fascial closure for trocar sites, especially in the wound that larger than $10 \mathrm{~mm} .{ }^{38}$ The placement of prophylactic mesh to prevent the incisional hernia was also reported by some researches. ${ }^{39}$ Thus, the improved cosmesis in LESS might be accompanied by increased risk of wound complications.

The pooled data showed lower analgesic requirement and shorter length of hospital stay for LESS compared with CL. It seems that LESS may have a better postoperative outcome; however, patients' subjective feeling and different hospital discharge criteria may introduce a reporting bias and a selection bias. The sensation of pain may be influenced by psychological factors. ${ }^{40}$ Patients undergoing LESS knew their incision wound was fewer, so they might tend to request for less analgesic and feel faster postoperative recovery. The actual benefit of LESS in terms of postoperative outcome remains further research.

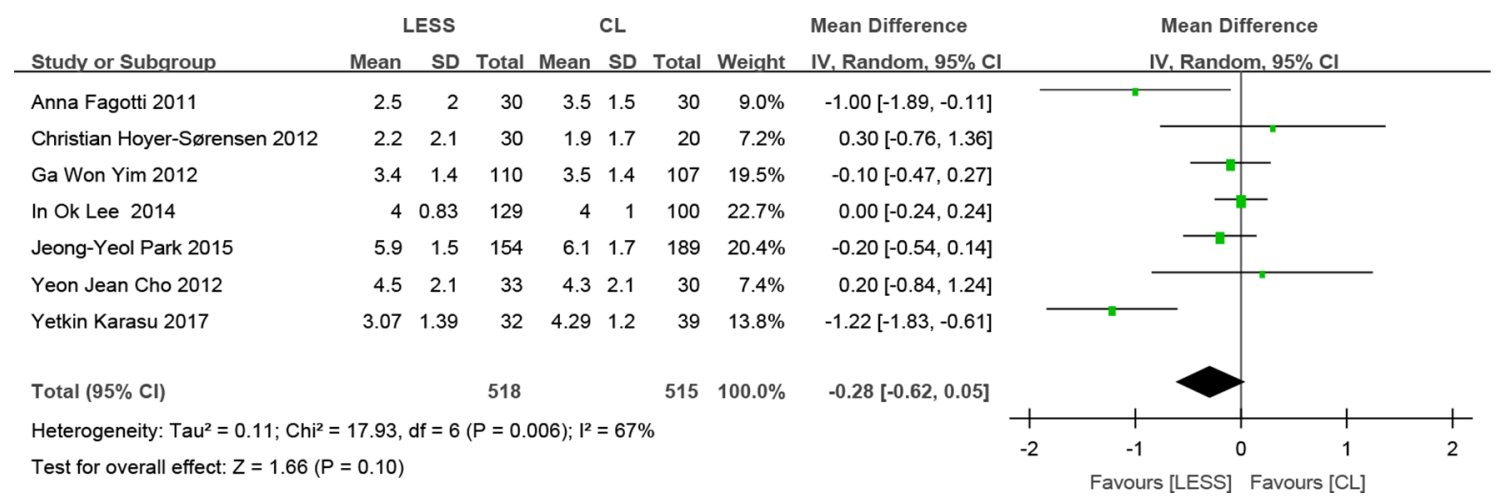

Figure 5 Forest plot and meta-analysis in evaluation of postoperative pain scores compared between LESS and CL of benign ovarian masses. CL, conventional laparoscopic surgery; LESS, laparoendoscopic single-site surgery. 


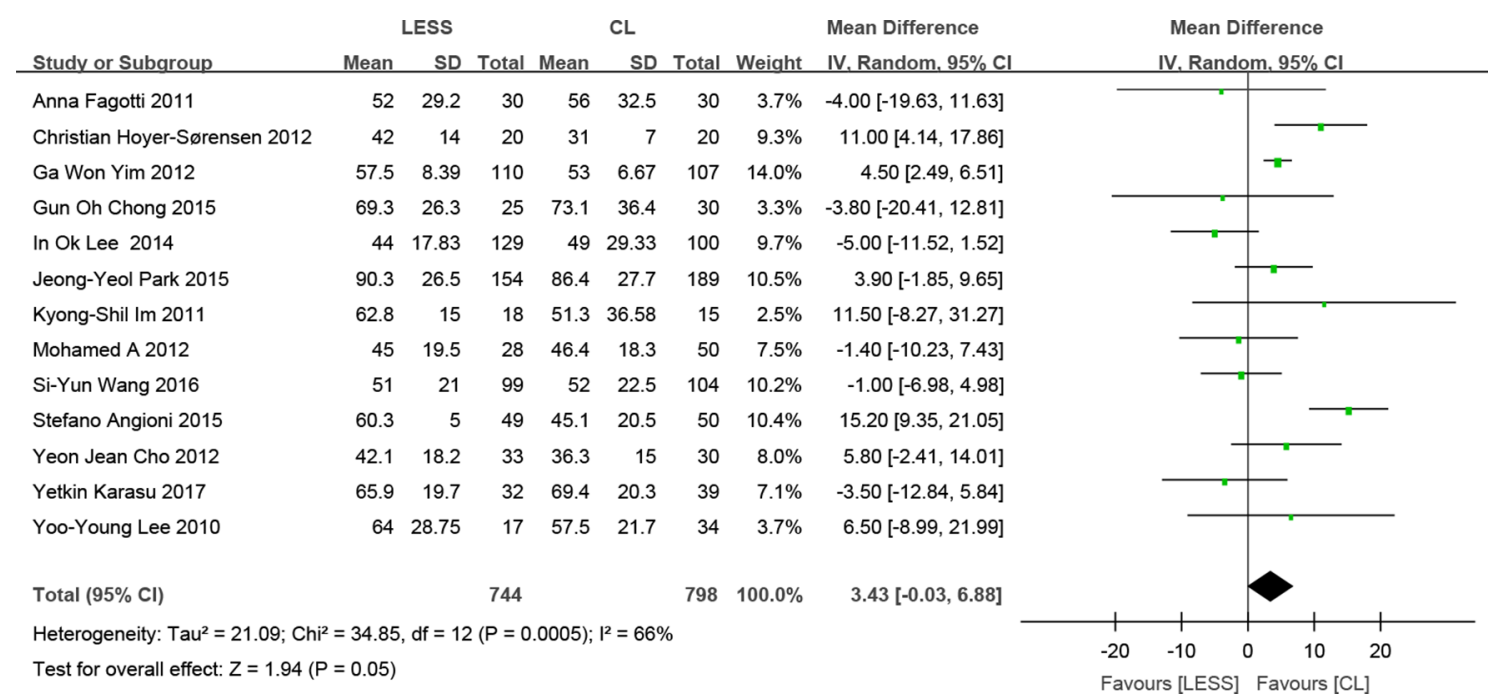

Figure 6 Forest plot and meta-analysis in evaluation of operative time compared between LESS and CL of benign ovarian masses. CL, conventional laparoscopic surgery; LESS, laparoendoscopic single-site surgery.

There are several limitations for this meta-analysis. First, there are only four RCTs with small sample sizes, so inadequate randomisation and blinding may increase the risk of bias. The differences in operative equipment and the experience of surgeons among studies also tend to increase the risk of bias. For this reason, we incorporate all eligible RCTs and non-RCTs in order to obtain a larger population and greater power. Second, there are significant heterogeneity of most items in this meta-analysis. The differences in tumour types, tumour size, age of patient, surgical indications, matching criteria and other factors among the studies might be responsible for the high heterogeneity. However, because all studies included in this meta-analysis are diverse both methodologically and clinically, a certain degree of heterogeneity is acceptable. Third, no subgroup analysis was performed among different histologic types of ovarian masses. The operative techniques and procedure of ovarian cystectomy and adnexectomy are different; however, limited data were provided in the present studies and more comparative studies are needed to verify the differences between the subgroups.

Nevertheless, this meta-analysis and systemic review is conducted at an appropriate time. LESS for benign ovarian masses has become as mature as CL surgery after nearly two decades of development and there are enough studies and data for inspection. We applied multiple strategies to search studies and strictly adhered the include and exclude criteria in order to ensure the quantity and quality of studies. Hence, this meta-analysis provides the most up-to-date and reliable information in this area.

\section{CONCLUSIONS}

This meta-analysis indicates that LESS has better postoperative recovery with lower postoperative analgesic

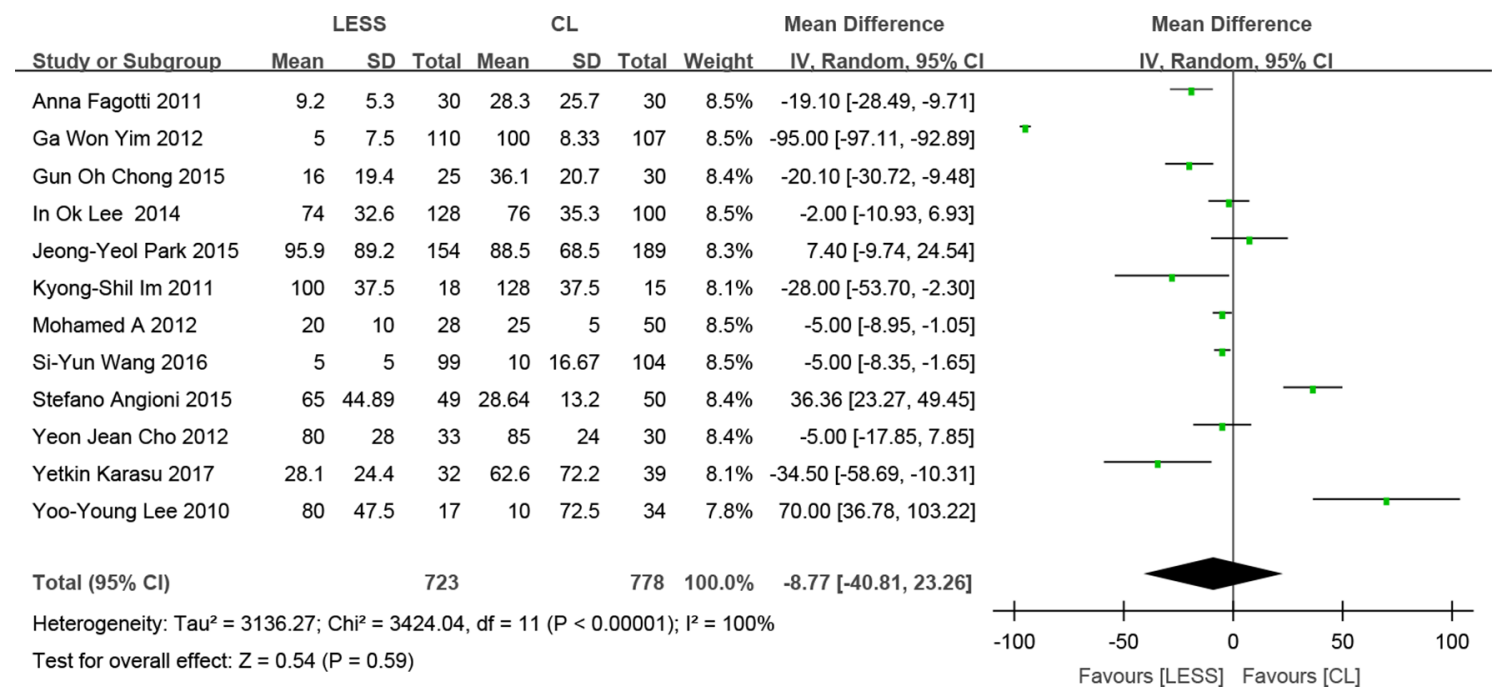

Figure 7 Forest plot and meta-analysis in evaluation of estimated blood loss compared between LESS and CL of benign ovarian masses. CL, conventional laparoscopic surgery; LESS, laparoendoscopic single-site surgery. 
A

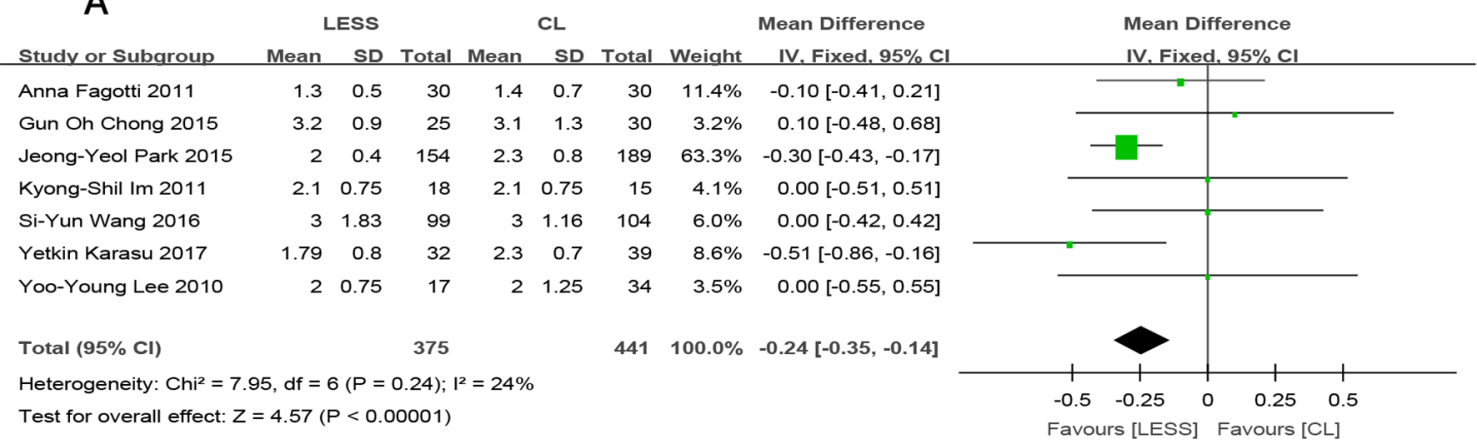

\section{B}

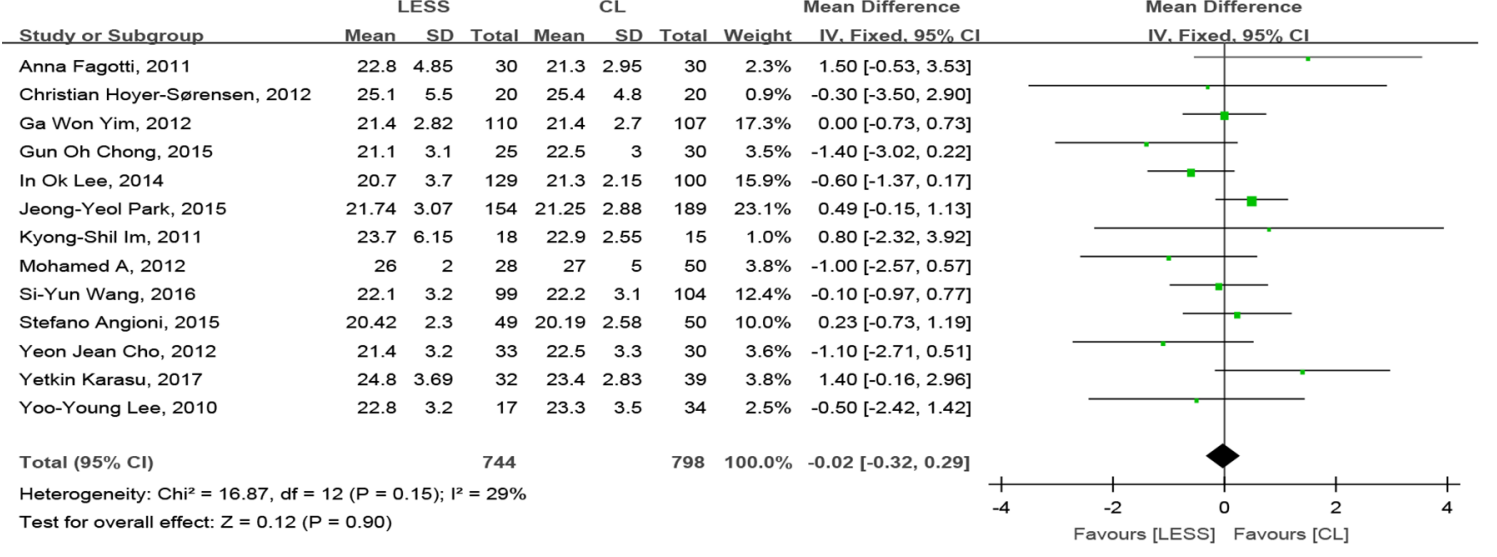

\section{C}

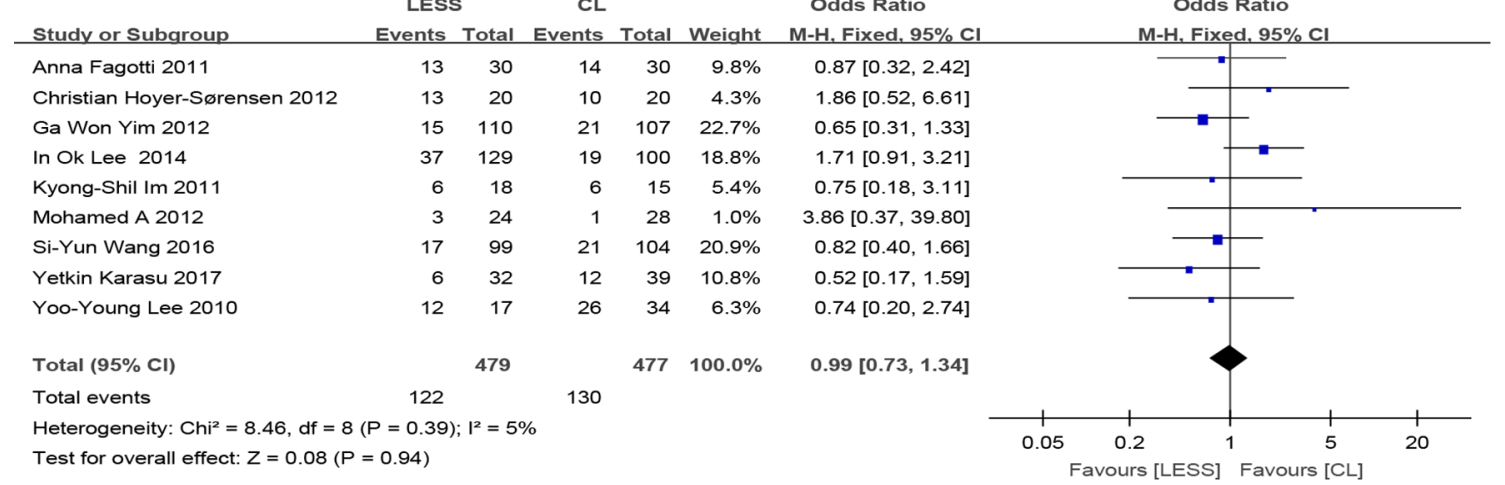

D

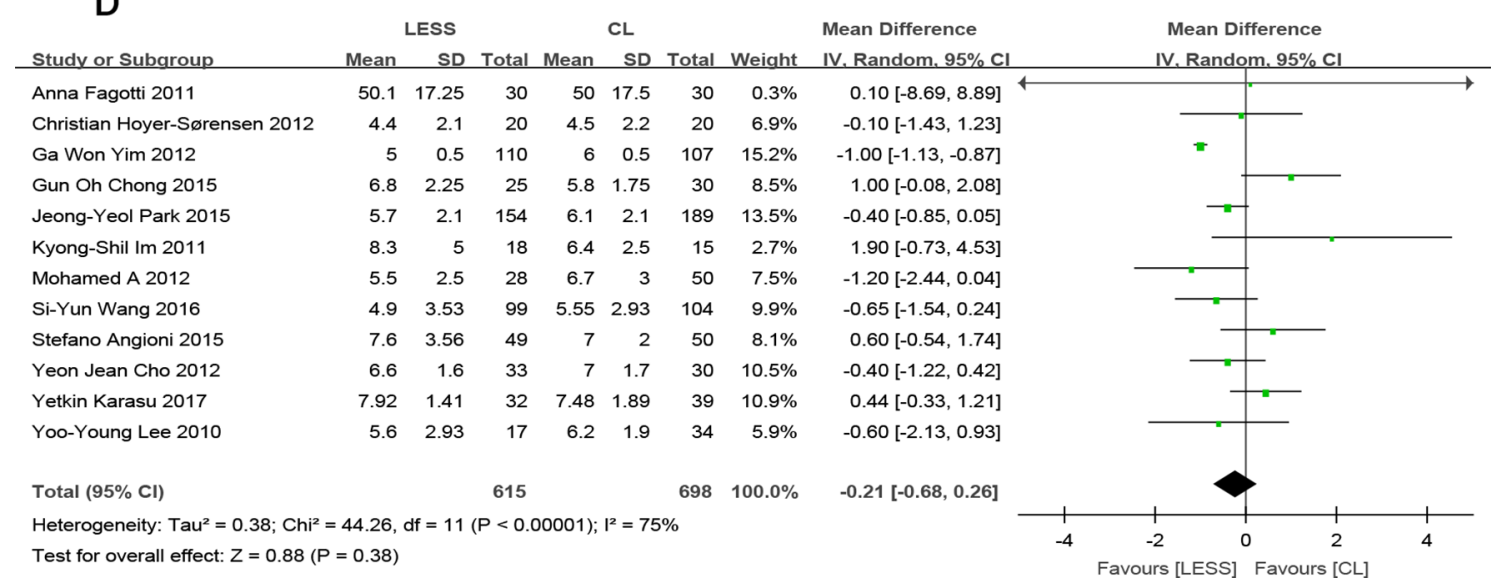

Figure 8 Perioperative outcomes following LESS versus CL of benign ovarian masses in terms of length of hospital stay (A), size of adnexal mass (B), body mass index (C), previous abdominal surgical history (D).CL, conventional laparoscopic surgery; LESS, laparoendoscopic single-site surgery. 


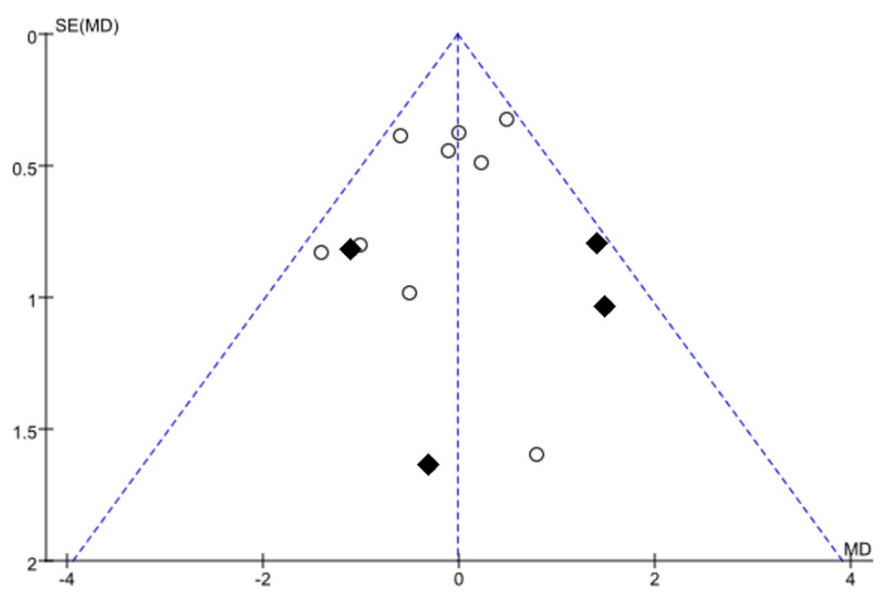

Figure 9 Funnel plots for illustrating publication bias of included studies. $\bullet$ RCTs; O, non-RCTs. MD, mean difference; RCT, randomised controlled trials.

consumption and shorter hospital stay, but CL is safer than LESS which has less perioperative complications and shorter operative time. Although our methodology is rigorous and our result is interpreted with caution, the inherent limitations of the included studies prevent us from reaching definitive conclusions. Well-designed, large multicentre RCTs with accurate measurement and extensive follow-up are awaited to estimate the comparative effectiveness of LESS and CL surgery for benign ovarian masses in the future.

Contributors Conceptualisation; project administration; writing-review and editing: YL and JC; data curation; resources: YL, ML, HY, JH and JC; formal analysis: YL and $\mathrm{JH}$; funding acquisition: $\mathrm{JH}$; investigation: $\mathrm{YL}, \mathrm{ML}, \mathrm{JH}$ and $\mathrm{JC}$; methodology: $\mathrm{YL}$; supervision: $\mathrm{ML}$ and $\mathrm{JC}$; writing-original draft: $\mathrm{YL}$.

Funding This research was funded by Medical Scientific Research Foundation of Guangdong Province of China, grant number A2017065.

Competing interests None declared.

Patient consent for publication Not required.

Provenance and peer review Not commissioned; externally peer reviewed.

Data availability statement Data are available upon reasonable request. Data extraction form and protocol available by request to drlinyun@foxmail.com.

Open access This is an open access article distributed in accordance with the Creative Commons Attribution Non Commercial (CC BY-NC 4.0) license, which permits others to distribute, remix, adapt, build upon this work non-commercially, and license their derivative works on different terms, provided the original work is properly cited, appropriate credit is given, any changes made indicated, and the use is non-commercial. See: http://creativecommons.org/licenses/by-nc/4.0/.

ORCID iD

Yun Lin http://orcid.org/0000-0003-3878-3496

\section{REFERENCES}

1 Pelosi MA, Pelosi MA, Gasparri ML. Laparoscopic hysterectomy with bilateral salpingo-oophorectomy using a single umbilical puncture. $N$ $J$ Med 1991;88:721-6.

2 Bradford LS, Boruta DM. Laparoendoscopic single-site surgery in gynecology: a review of the literature, tools, and techniques. Obstet Gynecol Surv 2013;68:295-304.

3 Liberati A, Altman DG, Tetzlaff J, et al. The PRISMA statement for reporting systematic reviews and meta-analyses of studies that evaluate health care interventions: explanation and elaboration. PLoS Med 2009;6:e1000100-34.
4 Phillips B. Grade: levels of evidence and grades of recommendation. Arch Dis Child 2004;89:489.

5 Wells G, Shea B, O'Connell D, et al. The Newcastle-Ottawa Scale(NOS) for assessing the quality of nonrandomised studies inmeta-analyses 2000.

6 Tarsilla M. Cochrane Handbook for systematic reviews of interventions. Wiley-Blackwell, 2008: 102-8.

7 Wan X, Wang W, Liu J, et al. Estimating the sample mean and standard deviation from the sample size, median, range and/or interquartile range. BMC Med Res Methodol 2014;14:135.

8 Higgins JPT, Thompson SG. Quantifying heterogeneity in a metaanalysis. Stat Med 2002;21:1539-58.

9 Hoyer-Sørensen C, Vistad I, Ballard K. Is single-port laparoscopy for benign adnexal disease less painful than conventional laparoscopy? A single-center randomized controlled trial. Fertil Steril 2012;98:973-9.

10 Cho YJ, Kim M-L, Lee SY, et al. Laparoendoscopic single-site surgery (less) versus conventional laparoscopic surgery for adnexal preservation: a randomized controlled study. Int $J$ Womens Health 2012;4:85-91.

11 Karasu Y, Akselim B, Kavak Cömert D, et al. Comparison of singleincision and conventional laparoscopic surgery for benign adnexal masses. Minim Invasive Ther Allied Technol 2017;26:278-83.

12 Fagotti A, Bottoni C, Vizzielli G, et al. Postoperative pain after conventional laparoscopy and laparoendoscopic single site surgery (less) for benign adnexal disease: a randomized trial. Fertil Steril 2011;96:255-9.

13 Im K-S, Koo Y-J, Kim J-B, et al. Laparoendoscopic single-site surgery versus conventional laparoscopic surgery for adnexal tumors: a comparison of surgical outcomes and postoperative pain outcomes. Kaohsiung J Med Sci 2011;27:91-5.

14 Bedaiwy MA, Starks D, Hurd W, et al. Laparoendoscopic singlesite surgery in patients with benign adnexal disease: a comparative study. Gynecol Obstet Invest 2012;73:294-8.

15 Yim GW, Lee M, Nam EJ, et al. Is single-port access laparoscopy less painful than conventional laparoscopy for adnexal surgery? A comparison of postoperative pain and surgical outcomes. Surg Innov 2013;20:46-54

16 Wang S-Y, Yin L, Guan X-M, et al. Single port transumbilical laparoscopic surgery versus conventional laparoscopic surgery for benign adnexal masses: a retrospective study of feasibility and safety, Chin Med J 2016:129:1305-10.

17 Park J-Y, Kim D-Y, Kim S-H, et al. Laparoendoscopic single-site compared with conventional laparoscopic ovarian cystectomy for ovarian endometrioma. J Minim Invasive Gynecol 2015;22:813-9.

18 Lee Y-Y, Kim T-J, Kim C-J, et al. Single port access laparoscopic adnexal surgery versus conventional laparoscopic adnexal surgery: a comparison of peri-operative outcomes. Eur J Obstet Gynecol Reprod Biol 2010;151:181-4.

19 Lee IO, Yoon JW, Chung D, et al. A comparison of clinical and surgical outcomes between laparo-endoscopic single-site surgery and traditional multiport laparoscopic surgery for adnexal tumors. Obstet Gynecol Sci 2014;57:386-92.

20 Chong GO, Hong DG, Lee YS. Single-Port (OctoPort) assisted extracorporeal ovarian cystectomy for the treatment of large ovarian cysts: compare to conventional laparoscopy and laparotomy. $J$ Minim Invasive Gynecol 2015;22:45-9.

21 Angioni S, Pontis A, Cela V, et al. Surgical technique of endometrioma excision impacts on the ovarian reserve. single-port access laparoscopy versus multiport access laparoscopy: a case control study. Gynecol Endocrinol 2015;31:454-7.

22 Ramirez PT. Single-Port laparoscopic surgery: is a single incision the next frontier in minimally invasive gynecologic surgery? Gynecol Oncol 2009;114:143-4.

23 Fan X, Lin T, Xu K, et al. Laparoendoscopic single-site nephrectomy compared with conventional laparoscopic nephrectomy: a systematic review and meta-analysis of comparative studies. Eur Urol 2012;62:601-12.

24 Moulton L, Jernigan AM, Carr C, et al. Single-Port laparoscopy in gynecologic oncology: seven years of experience at a single institution. Am J Obstet Gynecol 2017;217:610.e1-610.e8.

25 Corrado G, Cutillo G, Pomati G, et al. Single-access laparoscopic approach in the surgical treatment of endometrial cancer: a singleinstitution experience and review of literature. J Minim Access Surg 2016;12:360-5.

26 Song T, Kim MK, Kim M-L, et al. Laparoendoscopic single-site surgery for extremely large ovarian cysts: a feasibility, safety, and patient satisfaction study. Gynecol Obstet Invest 2014;78:81-7.

27 Fanfani F, Boruta DM, Fader AN, et al. Feasibility and surgical outcome in obese versus nonobese patients undergoing laparoendoscopic single-site hysterectomy: a multicenter casecontrol study. J Minim Invasive Gynecol 2015;22:456-61. 
28 Springer C, Inferrera A, Kawan F, et al. Laparoendoscopic singlesite versus conventional laparoscopic radical nephrectomy for renal cell cancer in patients with increased comorbidities and previous abdominal surgery: preliminary results of a single-centre retrospective study. World J Urol 2013;31:213-8.

29 Barletta JF, Senagore AJ. Reducing the burden of postoperative ileus: evaluating and implementing an evidence-based strategy. World J Surg 2014;38:1966-77.

30 Jeung IC, Lee YS, Song MJ, et al. Laparoendoscopic single-site total laparoscopic hysterectomy: clinical factors that affect operative times and techniques to overcome difficulties. J Minim Invasive Gynecol 2017;24:617-25.

31 Gasparri ML, Mueller MD, Taghavi K, et al. Conventional versus single port laparoscopy for the surgical treatment of ectopic pregnancy: a meta-analysis. Gynecol Obstet Invest 2018;83:329-37.

32 Pontis A, Sedda F, Mereu L, et al. Review and meta-analysis of prospective randomized controlled trials (RCTs) comparing laparoendoscopic single site and multiport laparoscopy in gynecologic operative procedures. Arch Gynecol Obstet 2016;294:567-77.

33 Marks JM, Phillips MS, Tacchino R, et al. Single-Incision laparoscopic cholecystectomy is associated with improved cosmesis scoring at the cost of significantly higher hernia rates: 1-year results of a prospective randomized, multicenter, single-blinded trial of traditional multiport laparoscopic cholecystectomy vs single-incision laparoscopic cholecystectomy. J Am Coll Surg 2013;216:1037-47.

34 Krajinovic K, Ickrath P, Germer C-T, et al. Trocar-Site hernia after single-port cholecystectomy: not an exceptional complication? J Laparoendosc Adv Surg Tech A 2011;21:919-21.

35 Balaphas A, Buchs NC, Naiken SP, et al. Incisional hernia after robotic single-site cholecystectomy: a pilot study. Hernia 2017;21:697-703.

36 Ichikawa M, Akira S, Mine K, et al. Evaluation of laparoendoscopic single-site gynecologic surgery with a multitrocar access system. $J$ Nippon Med Sch 2011;78:235-40.

37 Gunderson CC, Knight J, Ybanez-Morano J, et al. The risk of umbilical hernia and other complications with laparoendoscopic single-site surgery. J Minim Invasive Gynecol 2012;19:40-5.

38 Bhangu A, Fitzgerald JE, Singh P, et al. Systematic review and metaanalysis of prophylactic mesh placement for prevention of incisional hernia following midline laparotomy. Hernia 2013;17:445-55.

39 Markozannes G, Aretouli E, Rintou E, et al. An umbrella review of the literature on the effectiveness of psychological interventions for pain reduction. BMC Psychol 2017;5:31.

40 Higgins J, Thompson S, Deeks J, et al. Statistical heterogeneity in systematic reviews of clinical trials: a critical appraisal of guidelines and practice. J Health Serv Res Policy 2002;7:51-61. 